\title{
Variation in plasma cholinesterase activity among greenhouse workers, fruitgrowers, and slaughtermen
}

Flemming Lander, Svend Lings

\begin{abstract}
The purpose of the study was to compare the plasma cholinesterase (ChE) activities of 100 greenhouse workers and 43 fruitgrowers engaged in spraying insecticides with those of 113 slaughtermen who served as controls. The ChE activity in the greenhouse workers and fruitgrowers was not significantly lower than in the controls. Nevertheless the ChE activity of greenhouse workers declined with increasing exposure. The wearing of protective gloves appears to be of particular value for the safety of workers.
\end{abstract}

In Denmark exotic flowers are grown in heated greenhouses and insecticides are used throughout the year. Work in recently treated greenhouses is associated with exposure by inhalation or by skin contact with flowers, whose surfaces contain residues of pesticide. Air contained measurable insecticide concentrations some weeks after spraying. ${ }^{12}$ Fruitgrowers normally apply insecticides outdoors in the warm summer season only and the duration of exposure is short.

The plasma cholinesterase (ChE) activity is temporarily reduced by organophosphate (OP) and carbamate insecticides. Changes in individual $\mathrm{ChE}$ activity are considered a sensitive measure for uptake of these insecticides. ${ }^{3}$ The ChE activity is also influenced, however, by a variety of physiological and pathological conditions and some of these factors have to be taken into consideration in the evaluation of occupational exposure. ${ }^{4}$

The purpose of our study was to investigate the variation in ChE due to occupational exposure to $\mathrm{OP}$ and carbamate insecticides in greenhouse workers and fruitgrowers.

Department of Occupational Medicine, Odense University Hospital, DK-5000 Odense C, Denmark F Lander, S Lings

\section{Material and methods}

The study was carried out as a cross sectional investigation, with greenhouse workers and fruitgrowers as study groups and slaughtermen as the control group. From the national statistics trade register a random sample of 50 nursery gardens in the island of Funen, Denmark, was selected, ensuring a uniform distribution of different size firms and locations throughout the island. None refused to take part and 113 pesticide users contacted agreed to participate. Thirteen who had not applied relevant insecticides within the past three months were excluded. The fruitgrowers were selected from the local classified telephone directory. All 80 orchards listed were contacted, but only 50 , including 62 persons, still grew fruit. During the current spraying season only 43 persons had carried out spraying with relevant insecticides.

The nursery gardens and the orchards selected were contacted with short notice, less than a week before the project started (in September 1986 for nurseries and July 1987 for orchards). For the fruitgrowers this was immediately after the usual period of early summer spraying.

The control group consisted of 113 workers from two slaughterhouses. The members were selected at random from a total workforce of 685 . Blood samples were taken during the late summer of 1986 , simultaneously with the greenhouse workers but one year before the fruitgrowers. For this reason the possibility of minor differences in the composition of the analytical reagents or changes in laboratory procedure cannot be completely excluded. Plasma

Table 1 The background variables of greenhouse workers, fruitgrowers, and slaughtermen

\begin{tabular}{llll}
\hline & $\begin{array}{l}\text { Greenhouse } \\
\text { workers } \\
(n=100)\end{array}$ & $\begin{array}{l}\text { Fruit- } \\
\text { growers } \\
(n=43)\end{array}$ & $\begin{array}{l}\text { Slaughtermen } \\
(n=113)\end{array}$ \\
\hline Age (mean (range) y) & $36(16-68)$ & $54(27-79)$ & $36(16-66)$ \\
No of men (\%) & $92(92)$ & $41(95)$ & $104(92)$ \\
No of women (\%) & $8(8)$ & $2(5)$ & $9(8)$ \\
No of smokers (\%) & $33(33)$ & $12(28)$ & $70(62)$ \\
\hline
\end{tabular}


Table 2 Plasma alanineaminotransferase ( $A L A T)$-and cholinesterase (ChE) activities in greenhouse workers, fruitgrowers, and slaughtermen

\begin{tabular}{|c|c|c|c|c|}
\hline & \multirow[b]{3}{*}{ No } & \multirow[b]{2}{*}{$A L A T(U / l)$} & \multicolumn{2}{|l|}{$\operatorname{ChE}(k U / l)$} \\
\hline & & & Unadjusted & After adjustment * \\
\hline & & $(\operatorname{mean}(S D))$ & (mean) & $(\operatorname{mean}(S D))$ \\
\hline $\begin{array}{l}\text { Greenhouse workers } \\
\text { Fruitgrowers } \\
\text { Slaughtermen }\end{array}$ & $\begin{array}{r}100 \\
43 \\
113\end{array}$ & $\begin{array}{l}14 \cdot 5(7 \cdot 4)^{\star \star \star} \\
13 \cdot 3(5 \cdot 1) \\
24 \cdot 2(16 \cdot 3)\end{array}$ & $\begin{array}{l}4 \cdot 74 \\
4 \cdot 93 \\
5 \cdot 02\end{array}$ & $\begin{array}{l}4.76(0.96) \\
4.91(1.19) \\
5.03(1.03)\end{array}$ \\
\hline
\end{tabular}

^Adjusted for ALAT, smoking, and sex.

$\star \star \star F=22 \cdot 0, p=0 \cdot 0001$.

analysis conducted by The Department of Clinical Chemistry, Odense University Hospital, included measurement of cholinesterase (ChE) and alanineaminotransferase (ALAT) activities. The automatic titration method was employed to analyse $\mathrm{ChE}$ activity. ${ }^{5}$ The day to day variation in analysis of $\mathrm{ChE}$ activity was below $2.5 \%$. The activity of ALAT was analysed according to recommended international guidelines. ${ }^{6}$

A standardised interview was carried out at the time that blood samples were collected. Samples were taken by venepuncture, centrifuged two to four hours later, and the plasma frozen to $-20^{\circ} \mathrm{C}$. Plasma cholinesterase is a relatively stable enzyme at room temperature ${ }^{4}$ and changes in activity as a consequence of decay are likely to be minor.

Analysis of variance and multiple regression analysis were performed using the SPSS software at the local university computer centre. The level of significance selected was $5 \%$.

\section{Results and discussion}

Table 1 shows the distribution of some background variables. The mean age of the fruitgrowers was

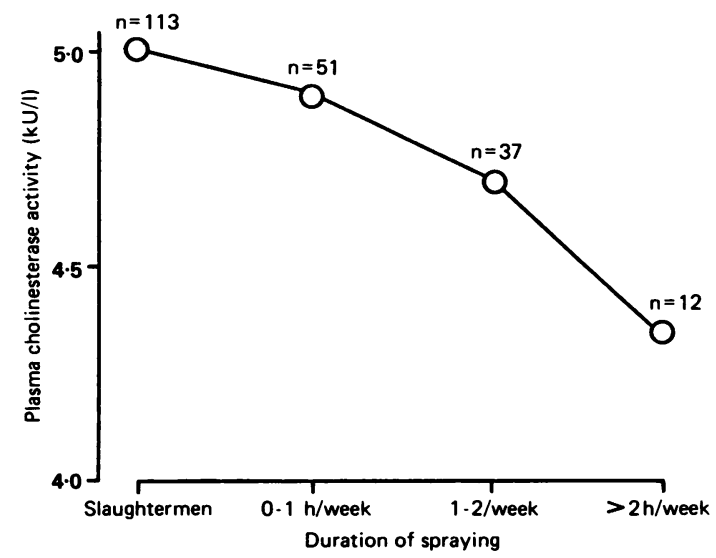

Figure 1 The relation between mean ChE activities of greenhouse workers and average weekly spraying time (h) with organophosphate and carbamate insecticides ( $F=1.98$, $p=0 \cdot 12$ ). considerably higher than that of the controls. There was a large overrepresentation of smokers among slaughtermen. According to the information received, none of the subjects were suffering from diseases or were using medicines that might affect ChE activity. The most common complaints were muscular pains, chronic bronchitis, and asthma.

Applying a stepwise multiple regression analysis on the ChE activity in the entire study group $(n=256)$, the influence of ALAT, smoking, age, and sex was analysed. The activity of ALAT and smoking exerted significant effects on ChE activity, but the combined effect accounts for only $7 \%$ of the total interindividual variance (multiple $R=0 \cdot 26$ ).

Table 2 shows the mean activity of ALAT among the three groups and the mean $\mathrm{ChE}$ activity adjusted for differences in ALAT, smoking, and sex. Only the activity of ALAT differed significantly between the three study groups with high mean activity in the group of slaughtermen. On average, $13 \%$ of slaughtermen, $2 \%$ of greenhouse workers, and none of the fruitgrowers had values above the upper normal limit for ALAT. Table 2 also shows that adjustment made little difference to means, and standard deviations

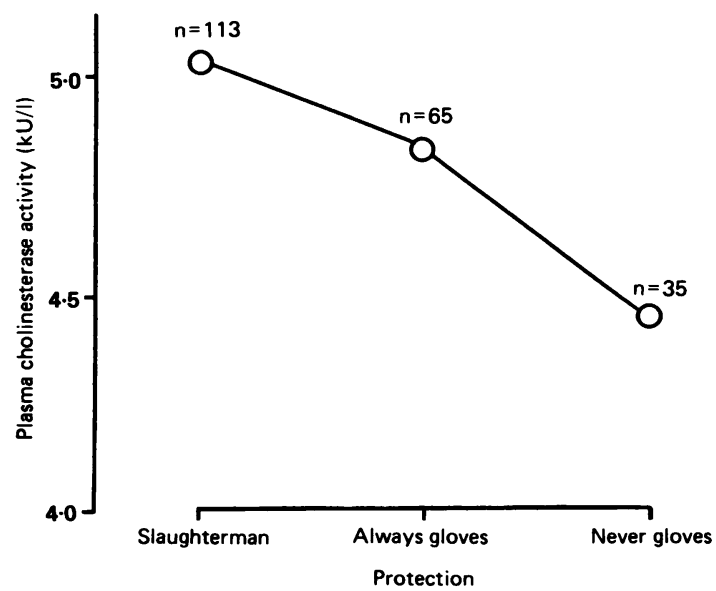

Figure 2 Effect of protective gloves on ChE activities of greenhouse workers applying organophosphate and carbamate insecticides $(F=4 \cdot 83, p=0.009)$. 
(SDs) were uniformly around $20 \%$ in each group.

Figure 1 shows the mean $\mathrm{ChE}$ activities according to duration of weekly spraying among the greenhouse workers. Apparently the activity declines with increasing duration of exposure, but the trend is not significant.

Applying a stepwise multiple regression analysis according to use of protective gloves, face mask, protective clothing, and rubber boots when applying insecticides, only the use of protective gloves exhibited a significant effect on $\mathrm{ChE}$ variation $(p=0.008)$, explaining $7 \%$ of the total interindividual variation in greenhouse workers. The use of protective equipment, including spraying from a tractor cab, had no effect on the ChE activity of fruitgrowers.

Figure 2 shows the mean $\mathrm{ChE}$ activities in slaughtermen and two groups of greenhouse workers, one with and the other without protective gloves. The use of gloves had a significant effect on exposure.

The study showed no significant difference in $\mathrm{ChE}$ activity between the groups exposed to pesticides and the slaughtermen, even after adjustment for differences in ALAT, smoking habits, and sex. Nevertheless within the group of greenhouse workers a negative correlation was found between the $\mathrm{ChE}$ activity and the average weekly spraying time. The $\mathrm{ChE}$ activity was also significantly influenced by the use of protective gloves.

1 Williams DT, Denley HV, Lane DA, Quan ESK. Real time monitoring of methomyl air levels during and after spraying in a greenhouse. Am Ind Hyg Assoc J 1982;43:190-5.

2 Williams DT, Denley HV, Lane DA. On site determination of sulfotep air levels in a fumigating greenhouse. An Ind Hyg Assoc J 1980;41:647-51.

3 Hayes W. Pesticides studied in man. Baltimore: Williams and Wilkins, 1982

4 Whittaker M. Monograph on human genetics: cholinesterase. Basel: Kager, 1986.

5 Jergensen $\mathrm{K}$. Automatic recording of cholinesterase activities. Scand J Clin Lab Invest 1959;11:282-4.

6 The Committee on Enzymes of the Scandinavian Society for Clinical Chemistry and Chemical Physiology. Recommended methods for determination of four enzymes in blood. Scand J Clin Lab Invest 1974;33:291-306.

Accepted 30 August 1990 